\title{
Issues in Japanese Health Policy and Medical Expenditure *
}

\author{
Yasushi Iwamoto $^{* *}$
}

January 2003

\begin{abstract}
This paper first discusses the past patterns of the national medical care expenditure and its future path. About 30 percent of the past growth was due to population aging and the remaining 70 percent was due to technological change. The medical expenditure is expected to increase by about 20 percent in 20 years due to population aging.

The latter half of the paper focuses on a reform plan of the health insurance for the elderly and presents some policy recommendations. One of the most serious problems in the health care market is that virtually no agents evaluate the quality of medical services or help improve it. It has not been clarified whether the rising medical costs are the result of waste or of necessity. Reform should attempt to make insurers play a more active role in the health care market as informed agents of patients. Dramatic outsourcing of the health insurance business to the private sector should be promoted.
\end{abstract}

JEL classification numbers: I18, I11, H51

Keywords: health insurance; medical cost; managed care

\footnotetext{
*Forthcoming in Toshiaki Tachibanaki ed., Sosical Security in Japan, Edward Elger. An earlier version of this paper was presented at the Second International Forum of the Collaboration Projects held in Tokyo on March 18-20, 2001. I would like to thank Robert Dekle for his helpful comments.

** Professor, Department of Economics, Hitotsubashi University, Kunitachi 186-8601, JAPAN. E-mail: iwamoto@econ.hit-u.ac.jp
} 


\section{Introduction}

Japanese citizens have recently worried about the rising burden of medical costs. Frequent reports of medical malpractice and accidents indicate, however, that the quality of medical services does not match the rising bill. This paper aims to discuss how Japanese policy makers could control the cost and quality of medical services. To this end, the paper first examines the past behavior of the national medical care expenditure and its future path. Possible reforms to slush medical costs and improve the quality of medical care are then proposed.

Per capita real medical expenditure is driven by two factors; a change in the population structure and the so-called "natural increase" (a change in input due to technological change). Section 2 of this paper shows that about 30 percent of the past growth was due to population aging and the remaining 70 percent was due to technological change. The paper also surveys the effect of population aging on future medical care expenditure and finds that medical expenditure will increase by around 20 percent in 20 years due to population aging.

Section 3 focuses on a reform of health insurance for the elderly and presents some policy recommendations. From the time the government started working on a fundamental reform plan of public health insurance, it took officials a very long time to assemble a reform plan of health insurance for the elderly. After failing to meet a deadline twice, the government and ruling parties finally reached an agreement of health care reform in November 2001. The agreed plan, however, has not resolved some fundamental problems. One of the most serious unresolved problems is that virtually no agents in the health care market evaluate the quality of medical services or help to improve it. It has not been clarified whether the rising medical costs are the result of waste or of necessity. Reforms should attempt to make insurers play a more active role in the health care market as informed agents of patients. Since the public sector has been dominating the health insurance business, dramatic outsourcing of the health insurance business to the private sector should be promoted. 


\section{The Effect of Aging on Medical Costs}

\subsection{Past Experiences}

The national medical expenditure in 2000 was 3,036 billion yen, and a Japanese citizen spent an average of 239 thousand yen a year for medical care. As shown in Figure 1, the ratio of medical expenditure to GDP increased in the 1990s and reached 6.3 percent in $1999 .{ }^{1}$ Since the share of medical expenditure of the elderly has been growing, many people think that the aging of population is a major reason for the increasing medical costs. However, focusing only on population aging will result in overlooking another important source. Even if the ratio of the elderly population to the total population remains stable, the overall growth of medical expenditure, including the non-elderly, is possible.

To determine the importance of the role of population aging in the increase in medical costs, Table 1 summarizes information from publications of the Ministry of Health, Labor, and Welfare and shows that the real per capita medical expenditure grew at a rate of 4.5 percent per annum from 1980 to 1999 . The contribution of population aging is obtained by changing only the population structure keeping the medical cost of each age group constant. The annual growth rate that is attributed to the change in the population structure was 1.4 percent from 1980 to 1997. Population aging increased the real per capita medical cost by 27 percent during this period. Therefore, about 30 percent of the medical cost growth is due to population aging. The "residual" growth (3.1 percent per annum) is attributed to a change in medical technology.

Table 1 reveals the following three points. First, population aging is not entirely responsible for the rising medical costs. Secondly, population aging in Japan contribute more to the rising medical costs than do population aging in other developed countries, as pointed by Niki (1995). For example, Cutler (1997) and Newhouse (1992) pointed out that the contribution of the change in the population structure in the United States

1 The medical care expenditure slightly decreased in 2000 due to the introduction of the public long-term care insurance. Before then a non-negligible part of population with disabilities had substituted medical services provided by health insurance for long-term care services. However, other data sources indicate that the upward trend of medical care costs has not qualitatively changed since 2000. Although resources devoted to both medical care and long-term care should be a focus of health policy for the elderly, issues in long-term care costs are beyond the scope of this paper. 
Figure 1: Total Medical Costs (The Ratio to GDP)

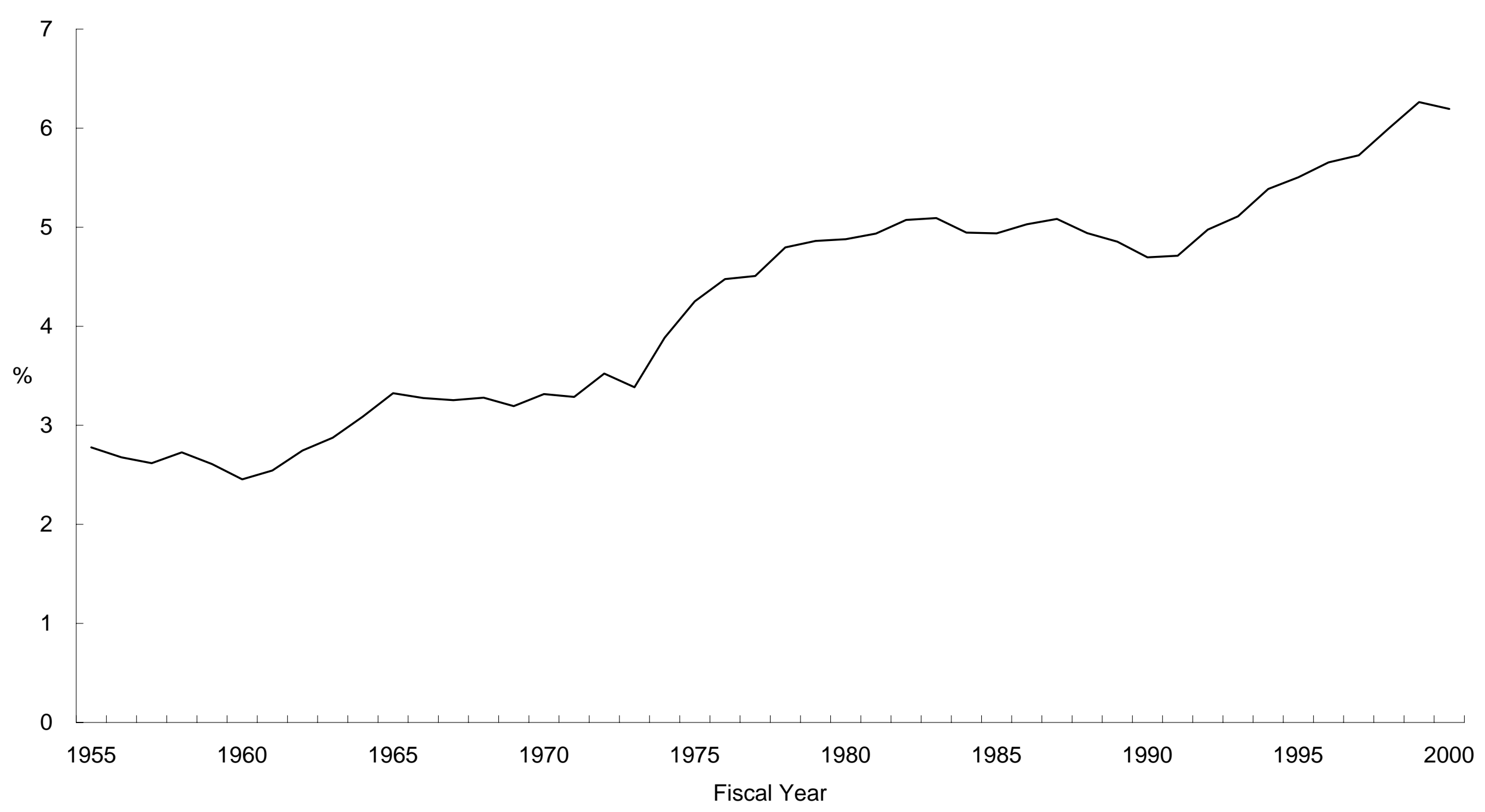


Table 1: Sources of Increase in Medical Costs (Percent)

\begin{tabular}{|c|c|c|c|c|c|}
\hline & \multicolumn{3}{|c|}{ Growth Rate } & \multicolumn{2}{|c|}{ Sources } \\
\hline & $\begin{array}{l}\text { Medical } \\
\text { costs }\end{array}$ & $\begin{array}{l}\text { Medical } \\
\text { costs per } \\
\text { capita }\end{array}$ & $\begin{array}{l}\text { Real } \\
\text { medical } \\
\text { costs per } \\
\text { capita }\end{array}$ & $\begin{array}{l}\text { Population } \\
\text { aging }\end{array}$ & $\begin{array}{l}\text { Others } \\
\text { (natural } \\
\text { increase) }\end{array}$ \\
\hline 1980 & 9.4 & 8.6 & 8.6 & 1.0 & 7.5 \\
\hline 1981 & 7.4 & 6.7 & 5.0 & 1.0 & 3.8 \\
\hline 1982 & 7.7 & 7.0 & 7.0 & 1.2 & 5.7 \\
\hline 1983 & 4.9 & 4.2 & 5.5 & 1.2 & 4.3 \\
\hline 1984 & 3.8 & 3.2 & 5.2 & 1.2 & 4.0 \\
\hline 1985 & 6.1 & 5.4 & 4.2 & 1.2 & 3.0 \\
\hline 1986 & 6.6 & 6.1 & 5.4 & 1.2 & 4.1 \\
\hline 1987 & 5.9 & 5.4 & 5.4 & 1.2 & 4.1 \\
\hline 1988 & 3.8 & 3.4 & 2.9 & 1.3 & 1.6 \\
\hline 1989 & 5.2 & 4.8 & 4.0 & 1.3 & 2.7 \\
\hline 1990 & 4.5 & 4.2 & 3.2 & 1.6 & 1.5 \\
\hline 1991 & 5.9 & 5.6 & 5.6 & 1.5 & 4.0 \\
\hline 1992 & 7.6 & 7.3 & 4.8 & 1.6 & 3.0 \\
\hline 1993 & 3.8 & 3.5 & 3.5 & 1.5 & 2.0 \\
\hline 1994 & 5.9 & 5.7 & 3.8 & 1.5 & 2.1 \\
\hline 1995 & 4.5 & 4.1 & 3.4 & 1.6 & 1.7 \\
\hline 1996 & 5.8 & 5.6 & 4.8 & 1.7 & 3.0 \\
\hline 1997 & 1.9 & 1.7 & 1.3 & 1.8 & -0.5 \\
\hline 1998 & 2.6 & 2.3 & 3.6 & 1.8 & 1.8 \\
\hline 1999 & 3.7 & 3.5 & 3.5 & 1.6 & 1.9 \\
\hline 2000 & -1.9 & -2.1 & -2.3 & 1.7 & -4.0 \\
\hline 1980-1999' & 5.4 & 4.9 & 4.5 & 1.4 & 3.1 \\
\hline
\end{tabular}

Source: National Medical Care Expenditure (Ministry of Health, Labor and Welfare).

Note: 1) A simple average of growth rates of each year. Since the drop of medical costs in 2000 was due to the shift of some long-term care spending from health insurance payments to long-term care insurance payments, the average excludes the year 2000 . 
Figure 2: Medical Costs by Age Group

8
7
6
5
4
3
2
1
0

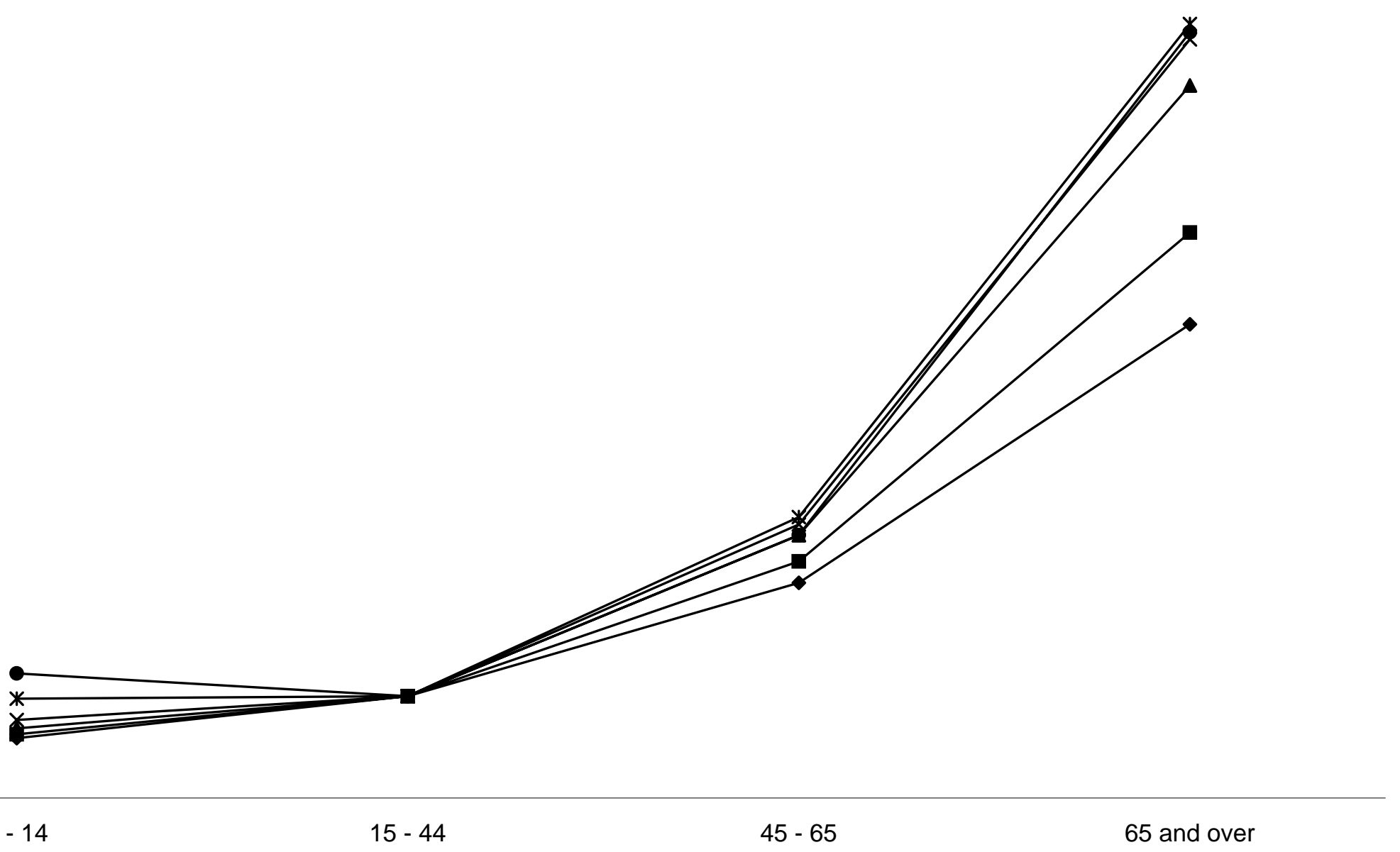

Source: National Medical Care Expenditure, various issues, Ministry of Labor, Health and Welfare.

Note: The medical cost of those aged 15-44 for each year is normalized to be one. 
was much smaller. ${ }^{2}$ Thirdly, the impact of aging became bigger in a later period. Since population aging in Japan is expected to accelerate in the near future, the attention needs to be paid to the future consequences.

Figure 2 shows the per capita medical expenditure by age group (0-14, 15-44, 45-64, 65 and over) in different years. The medical cost of those aged 15-44 for each year is normalized to be one. The medical cost of those aged 65 and over exhibit a higher growth than those of other age groups; from 4.6 times as big as the those of people aged 45-64 in 1977 to 8.3 times in 1999. A sharp increase was observed between 1980 and $1985 .^{3}$

\subsection{Future Projections}

If the elderly continue to incur higher medical costs than the non-elderly, the increasing aging population will raise the per capita medical costs of the entire population.

The Ministry of Health, Labor, and Welfare periodically provides a projection of the future medical costs. However, the methodology used by the Ministry includes an awkward procedure, i.e., they extrapolate the recent nominal growth rate. The predicted medical costs in 2025 varied wildly among predictions. For example, according to the 1994 projection, the medical cost in 2025 would be 141 trillion yen, but the 2001 projection indicated that it would be 81 trillion yen. This dramatic decline of nominal medical costs reflects the recent low nominal growth of medical expenditure, which is in turn due to the disinflation and deflation of the Japanese economy.

Since economists prefer a projection based on real costs, many alternative studies of estimating real medical costs have been conducted (for example, Iwamoto, Takeshita

\footnotetext{
${ }^{2}$ Newhouse (1992) estimated that 15 percent of the growth between 1950 and 1987 was explained by population aging. Cutler (1997) pointed out that population aging explained only 2 percent of the growth from 1940 to 1990.

3 The elderly aged 70 and over had received free medical care from 1973 to 1983 . In 1983, a fixed amount of out-of-pocket payment by the elderly was introduced, although the amount was tiny. If the total medical cost responds to the out-of-pocket expenses, the increased cost associated with the increased burden in this period is puzzling. However, evidence from other reforms of out-of-pocket payment rule supports the conventional wisdom that the medial cost responds negatively to the out-of-pocket expenses (see Iwamoto and Kishida, 2001). I conjecture that other technological factors might then have a significant effect on the growth of medical costs for the elderly.
} 
and Bessho, 1997; Niki, 1995; Nishimura, 1997; Ogura, 1994; Ogura and Irifune, 1990; Tokita et al. 1997). To estimate the real expenditure, it is necessary to predict what the inflation rate and technological change will be in the future. ${ }^{4}$ A conservative approach to predicting the future inflation rate of medical services is to assume it will be the same with the overall inflation rate. A more difficult problem is how to predict the future growth of medical service input. A naive assumption is that the real medical service input is proportional to the real income. When we combine these assumptions, the nominal medical costs for an average person are proportional to the nominal income. The effect of aging population is then isolated as follows. Take the recent data of medical costs of various age groups. Change only the population data to the projected future value (the government projection is commonly used). The total medical costs are the product of the per capita medical cost and the medical costs of an average person. Since the growth rate of the latter is equal to the income growth rate, the growth rate of the former reflects the change in the ratio of total medical expenditure to the income. When we focus on this ratio, we do not have to specify either the inflation rate or income growth rate.

Table 2 summarizes the existing research, which calculated the future medical costs using the above-mentioned approach. These studies show quite a similar pattern. For projections in the early 21st century, Ogura and Irifune (1990) estimated that the national medical expenditure would grow by 13.6 percent from 2001 to 2021 . Niki's (1995) projections showed 18.5 percent from 2000 to 2025. The growth between 2000 and 2020 was estimated as 22.7 percent by Nishimura (1997) and 19 percent by Tokita et al. (1997). A rough consensus is that the national medical expenditure will grow by about 20 percent in the first 20 years of this century.

\footnotetext{
${ }^{4}$ More than 90 percent of national medical care expenditure is paid by the public health insurance with the officially determined fee schedule. The estimation of the inflation rate of medical services (shown in Table 1) is based mainly on the change in this payment schedule.
} 
Table 2: Projections of Future Medical Costs

\begin{tabular}{|c|c|c|c|c|}
\hline \multicolumn{5}{|c|}{ Ogura and Irifune (1990) } \\
\hline Fiscal Year & \multicolumn{2}{|c|}{$\begin{array}{l}\text { Total Medical Costs } \\
\text { (trillion yen, in } 1986 \text { price) }\end{array}$} & \multicolumn{2}{|c|}{$\begin{array}{l}\text { Medical Costs per Capita } \\
\text { (yen, in } 1986 \text { price) }\end{array}$} \\
\hline 1986 & 15.23 & $(100)$ & 125,196 & $(100)$ \\
\hline 2001 & 19.59 & (128) & 151,572 & (121) \\
\hline 2021 & 22.26 & (146) & 179,397 & (143) \\
\hline \multicolumn{5}{|l|}{ Ogura (1995) } \\
\hline Fiscal Year & \multicolumn{2}{|c|}{$\begin{array}{l}\text { Total Medical Costs } \\
\text { (trillion yen, in } 1989 \text { price) }\end{array}$} & \multicolumn{2}{|c|}{$\begin{array}{l}\text { Medical Costs per Capita } \\
\text { (yen, in } 1989 \text { price) }\end{array}$} \\
\hline 1989 & 17.49 & $(100)$ & 142,075 & $(100)$ \\
\hline 2004 & 22.77 & $(130)$ & 178,765 & (121) \\
\hline 2024 & 25.41 & (145) & & \\
\hline \multicolumn{5}{|l|}{ Niki (1995) } \\
\hline Fiscal Year & \multicolumn{2}{|c|}{$\begin{array}{c}\text { Total Medical Costs } \\
\text { (trillion yen, in } 1990 \text { price) }\end{array}$} & \multicolumn{2}{|c|}{$\begin{array}{l}\text { Medical Costs per Capita } \\
\text { (yen, at in } 1990 \text { price) }\end{array}$} \\
\hline 1990 & 20.61 & $(100)$ & 166,720 & $(100)$ \\
\hline 2000 & 24.55 & (119) & 192,720 & (116) \\
\hline 2010 & 27.31 & (133) & 209,420 & (126) \\
\hline 2025 & 29.10 & (141) & 231,280 & (139) \\
\hline \multicolumn{5}{|c|}{ Iwamoto, Takeshita and Bessho (1997) } \\
\hline Fiscal Year & \multicolumn{2}{|c|}{$\begin{array}{l}\text { Total Medical Costs } \\
\text { (trillion yen, in } 1992 \text { price) }\end{array}$} & \multicolumn{2}{|c|}{$\begin{array}{l}\text { Medical Costs per Capita } \\
\quad \text { (yen, in } 1992 \text { price) }\end{array}$} \\
\hline \multicolumn{5}{|c|}{ 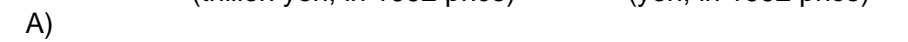 } \\
\hline 1992 & 21.13 & $(100)$ & 169,826 & $(100)$ \\
\hline 2010 & 27.64 & (131) & 211,968 & (121) \\
\hline 2025 & 29.52 & (140) & 234,623 & (138) \\
\hline \multicolumn{5}{|l|}{ B) } \\
\hline 2010 & 27.63 & (131) & 216,508 & (127) \\
\hline 2025 & 29.54 & (140) & 244,288 & (144) \\
\hline \multicolumn{5}{|c|}{ Nishimura (1997) } \\
\hline Fiscal Year & \multicolumn{2}{|c|}{$\begin{array}{l}\text { Total Medical Costs } \\
\text { (trillion yen, in } 1994 \text { price) }\end{array}$} & \multicolumn{2}{|c|}{$\begin{array}{l}\text { Medical Costs per Capita } \\
\quad \text { (yen, in } 1994 \text { price) }\end{array}$} \\
\hline 1994 & 25.00 & $(100)$ & 199,818 & $(100)$ \\
\hline 2000 & 27.86 & (111) & 218,707 & (109) \\
\hline 2005 & 30.24 & (121) & 233,792 & (117) \\
\hline 2010 & 32.03 & (128) & 245,634 & (122) \\
\hline 2015 & 33.30 & (133) & 256,089 & (128) \\
\hline 2020 & 34.18 & (137) & 266,313 & (133) \\
\hline 2025 & 34.19 & (137) & 271,768 & (135) \\
\hline 2030 & 33.72 & (135) & 274,209 & (137) \\
\hline 2035 & 33.15 & (133) & 274,668 & (137) \\
\hline 2040 & 33.63 & (135) & 286,725 & (143) \\
\hline \multicolumn{5}{|c|}{ Tokita et al. (1997) } \\
\hline Fiscal Year & \multicolumn{2}{|c|}{$\begin{array}{l}\text { Total Medical Costs } \\
\text { (trillion yen, in } 1993 \text { price) }\end{array}$} & \multicolumn{2}{|c|}{$\begin{array}{l}\text { Medical Costs per Capita } \\
\quad \text { (yen, in } 1993 \text { price) }\end{array}$} \\
\hline 1993 & 20.17 & $(100)$ & 161,440 & $(100)$ \\
\hline 2000 & 22.51 & (112) & 177,395 & (110) \\
\hline 2005 & 23.86 & (118) & 186,868 & (116) \\
\hline 2010 & 25.08 & (124) & 196,516 & (122) \\
\hline 2015 & 26.44 & (131) & 209,104 & (130) \\
\hline 2020 & 26.79 & (133) & 215,817 & (134) \\
\hline 2025 & 26.39 & (131) & 218,256 & (135) \\
\hline
\end{tabular}

Note: Numbers in parentheses are normalized so that the bese year has 100.

Medical costs per capita of Ogura and Irifune (1990), Ogura (1995), Nishimura (1997), Tokita et al. (1997), total medical costs of Niki (1995) and Iwamoto, Takeshita and Bessho (1997), and case (B) of Iwamoto, Takeshita, and Bessho (1997) are the author's calculation. Ogura and Irifune (1990) and Ogura (1995) relied on their own population projections. Case (B) of Iwamoto, Takeshita and Bessho (1997) relied on the official population projection as with January 1997. Other studies employed the official population projection as with September 1992. 


\section{Debates on a Comprehensive Reform of the Health Insurance for the Elderly}

\subsection{Reform Debates Entangled}

Since the growth rate of medical expenditure has exceeded that of the national income, the financial condition of health insurance system has continuously deteriorated. The necessity of a comprehensive reform of the health insurance system has been recognized since the Medical Insurance Council of the former Ministry of Health and Welfare commenced a discussion in March 1995. The toughest problem to be tackled is how to finance the medical costs of the elderly, who spend much more and contribute less than other sectors of the population.

Under the current system, workers and their families are enrolled in Employee's Health Insurance (EHI), and retired workers and their families belong to the National Health Insurance (NHI), which is mainly for the self-employed and the elderly. If the NHI tries to maintain an independent budget, its financial situation will seriously worsen. The government, then, is forced to subsidize the NHI. When the Health Service for the Elderly (Roken in Japanese) was established in 1983, the financing scheme of the medical costs of the elderly was fundamentally changed. First of all, the Roken is in a unique position because it is responsible for only the provision of benefits, while other health insurance subsystems are responsible for both the provision of benefits and the collection of insurance premiums. After the establishment of the Roken, the elderly remain enrollees of existing systems, which they pay premiums, but they receive benefits from the Roken. The Roken itself does not collect a premium. The medical costs of the elderly are financed from transfers from other health insurance groups. Roughly speaking, each subsystem pays to the Roken in proportion to the number of their enrollees. ${ }^{5}$ The medical costs of the elderly are effectively supported by the rest of the public health insurance subsystems. However, the EHI is not pleased to have to subsidize the Roken. The increased share of medical costs of the elderly has caused a substantial increase in transfers from other insurance groups, thus worsening the financial conditions of the EHI.

From the time the former Ministry of Health and Welfare started to work on a reform plan of public health insurance in 1995 , it took officials a very long time to assemble a

\footnotetext{
${ }^{5}$ Actually, the exact formula of transfers is slightly complicated.
} 
concrete reform plan of health insurance for the elderly. When the out-of-pocket payment of employees and the elderly was raised in September 1997, the government could not provide a plan of fundamental reform and promised to deliver a plan by FY 2001. After heated debates, the government did not reach a conclusion again, and then postponed the reform until FY 2002.

To meet the new deadline, the policy makers had to finalize a plan in 2001. In the report published in March 2001, the Ministry of Health, Labor and Welfare presented four candidate plans of a comprehensive reform of health insurance for the elderly. The first plan was to establish an independent health insurance group for the elderly with heavy governmental subsidization. The second plan was to move retired workers into the EHI. The third plan was to introduce a risk adjustment scheme among health insurance groups. The forth plan was to unite public health insurance subsystems and launch a new single insurance group for the total population.

The Ministry of Health, Labor and Welfare proposed a reform plan in September 2001. According to this plan, the eligible age of the Roken would be raised from 70 to 75. A 10 percent coinsurance rate would be applied to elderly participants aged 75 and over (20 percent for those aged 70-74). Fifty percent of medical expenses would be subsidized by the national budget, while 30 percent of medical expenses is currently subsidized. The coinsurance rate for the employees would be raised from 20 percent to 30 percent. The Ministry's plan also proposed to introduce a cap system that would keep the growth rate of medical costs for the elderly within the growth rate of the per capita GDP (if the medical costs grew higher, the health insurance would automatically drop the price that they paid). The Ministry of Finance and the Council on Economic and Fiscal Policy each advocated a cap system that would keep the total medical cost growth within the rate of economic growth. ${ }^{6}$

In November 29, 2001, the government and ruling parties finally reached an agreement concerning the reform plan. While the increase in the eligible age for the Roken was in agreement with the Ministry of Health, Labor and Welfare plan, the hike of out-of-pocket expenses for the elderly was met with criticism. A 10 percent

6 This episode suggests that the health insurance reform was an extraordinary, complicated event, because it is very exceptional for the Ministry of Finance to propose its own reform plan about the policy that another ministry is in charge of. 
coinsurance rate would be applied to those aged 70 and over (20 percent for the high-income households). ${ }^{7}$ The idea of the cap system, which was unpopular with doctors, was dropped from the plan.

\subsection{What went wrong?}

The agreed reform plan is a mismatch of compromises. It partially incorporates the first candidate of the March 2001 report by increasing the subsidies by the national budget. It also partially incorporates the second candidate of the report by moving retired workers aged 70-74 and their dependents to the Taishokusha Iryo, which is effectively a part of health insurance for employees. ${ }^{8}$ The agreed reform plan does not give a final answer of how to finance the medical costs of the elderly. Neither does it solve the problem of the increasing medical costs. Therefore, another reform will be needed within a few years if medical costs continue to grow.

The large delay of the overhaul of the health care system comes from addressing the problems in the wrong order. Since the total medical expenditure is not likely to be changed substantially by the current reform plan, reducing somebody's burden will increase somebody else's. The finance of health insurance is essentially a zero sum game. While a cap system will automatically cut expenses, its effect on the quality of medical service is ambiguous. Since Japan has virtually no workable quality evaluation system, there is no guarantee that the cap system will cut only inefficient medical treatments. Moreover, we will not be able to check whether the quality of the medical services will stay the same or decline. The problem that should be addressed first is how to make the provision system more transparent and efficient. Until people are convinced of the quality of medical services, a satisfactory fundamental reform of health insurance will not be realized.

The consumer's demand for better and cheaper services is not different between the health care market and other markets. In the market economy, usually, consumer choice puts pressure upon providers, thus resulting in the improvement of quality and the reduction of prices. However, due to asymmetric information, consumer sovereignty has

7 This hike was realized in October 2002. A 30 percent of coinsurance rate for employees was applied in April 2003.

${ }^{8}$ The Taishokusha Iryo currently consists of retired workers aged under 69 and their dependents. 
not been well established in the area of health care. A promising idea to remedy the absence of consumer sovereignty is to have a professional third party acting as an informed agent for patients. Managed care belongs to this idea; an insurer plays a more active role than in traditional insurance policies. ${ }^{9}$

A naive application of managed care will not be workable in Japan because a dominant part of health insurance is operated by the public sector, which is not supposed to become a driving force of the market mechanism. Japanese regulators have basically given up measuring the quality, and they have targeted the ratio of medical expenditure to the national income. As a result, the actions of improving the quality of services in Japan lag far behind those of the United States, where private companies run health insurance business. Our government has just started promoting Evidence-Based Medicine, which has already been incorporated into medical practices outside Japan.

\subsection{The Japanese Way of Promoting Managed Care}

Providers of medical services have not received a strong market force under the dominance of the public health insurance system. ${ }^{10}$ Therefore, our health policy has to outsource a substantial part of the public health insurance business to the private sector and to make the role of insurers more active. An action toward this direction has been initiated not by the Ministry of Health, Labor and Welfare but by the Regulatory Reform Council (Sogo Kisei Kaikaku Kaigi), which placed health care as one of the six most important areas of promoting regulatory reforms in 2001. Based on the plan by the Regulatory Reform Council, the Reform Work Schedule (Kaikaku Kotei Hyo, assembled by the Council on Economic and Fiscal Policy, September 2001) contains important items of facilitating the activities of insurers. The insurer will be able to do the ex post review of medical practice, while the current legislation forces them to delegate it to special public agencies (Shiharai Kikin and Kokuho Rengokai). The

9 Glied (2000) surveys issues in managed care.

10 Japanese medical expenses vary widely among regions. The prefecture with the highest per capita medical costs spent 1.53 times as much as the prefecture with the lowest cost in 1999, even after adjusting for the difference in the population structure. The large regional variations have been considered as evidence that Japanese medical practices are not quite standardized. A recent report of the regional variations has pointed out that the excess capacity of medical institutions drives medical costs up by inducing the demand for medical care (Chiikisa Kenkyukai, 2001). 
insurer will also be able to make a contact directly with medical service providers and apply a different payment schedule from that determined by the public health insurance.

When the reform actions advocated by the Reform Work Schedule are realized, the insurer will be given an opportunity to play a more active role in the health care market. Particularly, the design of a payment schedule will play an important role in improving the medical practice. The introduction of a prospective payment system (PPS) has been advocated in the reform of payment schedule because the insurer will evaluate the quality of providers and give them incentives through the reward based upon outcome rather than input.

In 1990, the public health insurance first introduced a PPS into the inpatient fee of the elderly. The PPS was later introduced into other areas at a slow pace. What will be the consequence of the PPS? If medical service providers seek profit, the introduction of the PPS will result in a lower service input. Its effect on quality would be ambiguous, when the original fee-for-service payment distorts the behavior of providers. An early study of the consequences of the introduction of the PPS in 1990 is Takagi (1993), which provides a case study of a hospital. A comparison before and after the introduction of the PPS indicated that the hospital had substantially reduced the utilization of drugs and screening. In terms of the numbers of deaths at the hospital, the quality of medical services did not show a significant decline.

An important difference from the US Medicare PPS is that Japanese providers choose the PPS or a fee-for-service schedule. While the choice cannot be given on a case-by-case basis, the providers will choose the PPS if the expected revenue under the PPS is higher than those under the fee-for-service schedule. Kawai and Maruyama (2000) focused on the introduction of PPS to outpatient care for chronic diseases of the elderly and outpatient care for infant children in April 1996, and they found that providers respond to incentives given by the PPS. A hospital that expected a lower average medical cost under the fee-for-service schedule would choose PPS. Since policy makers intended to involve many medical care providers in the PPS, the payments under the PPS became generous for hospitals that spend less resources on patients. Therefore, the PPS was not helpful in reducing medical costs. The mandatory application of PPS has to be considered as a policy option. 


\section{Concluding Remarks}

To determine whether medical costs can be cut without deteriorating the quality and how to do so, we need to have a satisfactory system to evaluate the quality of medical care. Thus creation of a workable evaluation system should be given top priority.

A market-oriented approach, competition trough a choice by informed agents of patients will help to improve the efficiency of health care provision. The public operation of health insurance has deprived the vital activities of the private sector. The introduction of managed care into the world governed by publicly operated universal health insurance will require a different strategy from that needed in a world dominated by private health insurance. Therefore, a naive imitation of US experiences may not be workable, and the Japanese policy makers will have to design a system that fits the Japanese situation. The provision and financing of health care varies among countries. The ongoing Japanese experience will help us understand the interaction of the market and institutions more thoroughly.

In policy debates, a totally ignored issue is whether we have to pre-fund the health insurance against the expected rise of future medical expenses; some academic scholars, however, have discussed it (Iwamoto, 2002; Nishimura, 1997; and Suzuki, 2000). Since we have more problems to address than problems resolved, continued effort will be necessary to pursue a better health policy. 


\section{References}

Chiikisa Kenkyukai ed. (2001), Iryohi no Chiikisa (Regional Variations in Medical Expenditure), Tokyo: Toyokei Shinposha (in Japanese).

Cutler, David M. (1997), "Public Policy for Health Care," in Alan J. Auerbach ed., Fiscal Policy: Lessons from Economic Research, Cambridge, MA: MIT Press, pp. 157-198.

Glied, Sherry (2000), "Managed Care," in Anthony J. Culyer and Joseph P. Newhouse eds., Handbook of Health Economics, Vol. 1A, Amsterdam: Elsevier, pp. 707-753.

Iwamoto, Yasushi (2002), "Koreisha Iryo Hoken Seido no Kaikaku (Reform of Health Insurance for the Elderly)," Nihon Keizai Kenkyu, No. 44, March, pp. 1-21 (in Japanese).

Iwamoto, Yasushi and Kensaku Kishida (2001), “An Estimation of the Price Elasticity of Medical Care: Evidence from Japanese Policy Reforms During 40 Years," mimeo.

Iwamoto, Yasushi, Satoshi Takeshita, and Masashi Bessho (1997), "Iryo Hoken Zaisei to Kohi Futan (Public Health Insurance and Government Subsidies)," Finansharu Rebyu, No. 43, November, pp. 174-201 (in Japanese).

Kawai, Hiroki, and Shiko Maruyama (2000), "Hokatsu Barai Sei Donyu ga Iryohi to Shinryo Mitsudo ni Oyoboshita Eikyo ni Kansuru Bunseki: Rojin Mansei Shikkan Gairai narabini Nyuyouji Gairai ni Kanshite (An Analysis of the Effect of the Inclusive Payment System on Costs and Intensity of Care: The Cases of Elder Outpatients and Infant Outpatients)," Iryo Keizai Kenkyu, Vol. 7, pp. 37-64 (in Japanese).

Newhouse, Joseph P. (1992), “Medical Care Costs: How Much Welfare Loss?” Journal of Economic Perspectives, Vol. 6, No. 3, Summer, pp. 3-21.

Niki, Ryu (1995), Nihon no Iryohi: Kokusai Hikaku no Shiten kara (Medical Care in Japan: From the Comparative Perspective), Igaku Shoin (in Japanese).

Nishimura, Shuzo (1997), “Choki Tsumitate Gata Iryo Hoken Seido no Kanosei ni Tsuite (On the Possibility of Full-funded Social Health Insurance)," Iryo Keizai Kenkyu, Vol. 4, December, pp. 13-34 (in Japanese). 
Ogura Seiritsu (1994), “The Cost of Aging: Public Finance Perspectives for Japan,” in Yukio Noguchi and David A. Wise eds., Aging in the United States and Japan, Chicago: The University of Chicago Press, pp. 139-173.

Ogura, Seiritsu and Tsuyoshi Irifune (1990), "Waga Kuni no Jinko no Koreika to Kaku Kouteki Iryo Hoken no Shushi ni Tuite (Population Aging and the Financing of Public Health Insurance)," Finansharu Rebyu, No. 17, August, pp. 51-77 (in Japanese).

Suzuki, Wataru (2000), "Iryo Hoken ni Okeru Sedai Kan Fukohei to Tsumitatekin wo Motsu Fea na Zaisei Hosiki heno Iko (A Proposal for Removing Intergenerational Inequity from the Japanese Health Insurance System)," Nihon Keizai Kenkyu, March, pp. 88-104 (in Japanese).

Takagi, Yasuo (1993), “Rojin Byoin ni Okeru Kaigo Ryoku Kyoka to Hiyo Manpawa no Henka: Waga Kuni no Rojin Choki Kea no Genjo to Iryo Shisetsu no Henbo (Introduction of an Inclusive Per-Diem Reimbursement System for Geriatric Care and its Effects Reductions the Costs of Medication and Diagnostic Tests and an Improvement in the Patient's ADL," Kikan Shakai Hosho Kenkyu, Vol. 28, No. 4, March, pp. 395-404 (in Japanese).

Tokita, Tadahiko et al. (1997), “The Present and Future National Medical Expenditure in Japan," Keizai Bunseki, No. 152, September. 